\title{
Processo de revalidação de diplomas em medicina na Universidade do Estado da Bahia (UNEB)
}

\section{Process of revalidation of medical degrees at the Universidade do Estado da Bahia (UNEB)}

\author{
Ivan Luiz Novaes ${ }^{1}$ \\ Lídia Boaventura Pimenta ${ }^{2}$ \\ Rodrigo Luiz Lasse Ferreira ${ }^{3}$
}

\section{Resumo}

A função social da instituição universitária implica em fornecer respostas às demandas contemporâneas. Este artigo apresenta subsídios para o processo da revalidação de diplomas de medicina no âmbito da Universidade do Estado da Bahia (Uneb), utilizando a revisão normativa. Para tal fim, apresenta algumas reflexões sobre a função social da universidade e alguns dilemas acerca da condução de seus processos de gestão. As reflexões aqui apresentadas, decorrem da necessidade de as universidades se engajarem no enfrentamento da pandemia da Covid-19 e contribuírem com a eminente necessidade de médicos para atuar na rede de saúde. Este artigo, portanto, reuni os principais dispositivos normativos, adotados pela referida Universidade para consubstanciar os processos de revalidação de diplomas de médicos, como também descreve as estratégias utilizadas por essa Instituição na condução de tal processo.

Palavras-chave: Administração pública; Gestão da educação superior; Revalidação de diploma; covid-19.

\begin{abstract}
The social function of the university institution implies providing answers to contemporary demands. This article presents subsidies for the process of revalidation of medical degrees in the scope of the Universidade do Estado da Bahia (Uneb), using the normative review. To that end, it presents some reflections on the social function of the university and some

\footnotetext{
${ }^{1}$ Doutorado em Educação, Université de Sherbrooke - Canadá. Professor do Programa de Pós-Graduação Gestão e Tecnologias Aplicadas à Educação (GESTEC) da Universidade do Estado da Bahia-UNEB; orcid: https://orcid.org/0000-0003-2607-2304; e-mail: ilnovaes@uneb.br

2 Professora do Programa de Pós-Graduação Gestão e Tecnologias Aplicadas à Educação-Universidade do Estado da Bahia (GESTEC/UNEB). orcid: https://orcid.org/0000-0003-0936-9202 ; e-mail: lpimenta@uneb.br

${ }^{3}$ Mestre em Gestão e Tecnologias Aplicadas à Educação (GESTEC)-Universidade do Estado da Bahia-UNEB. orcid: https://orcid.org/0000-0002-0034-1986; e-mail: rlferreira@uneb.br
} 
dilemmas about the conduct of its management processes. The reflections presented here are due to the need for universities to engage in facing the Covid-19 pandemic and to contribute to the eminent need for doctors to work in the health network. This article, therefore, brought together the main normative provisions adopted by the said University to substantiate the processes of revalidation of doctors' diplomas, as well as describing the strategies used by that Institution in conducting such a process.

Keywords: Public administration; Higher education management; Certificate revalidation; Covid-19.

\section{Introdução}

O século XXI traz de volta à humanidade a experiência de viver em estado de pandemia, algo que a maioria das pessoas considerava pertencer a séculos passados, como ocorreu, por exemplo, com a peste bubônica, varíola, gripe espanhola, tifo, entre outras doenças. A concepção de que o avanço dos estudos e pesquisas na área da medicina, acompanhados do desenvolvimento tecnológico, poderiam impedir a ocorrência de uma pandemia no planeta, ainda não se concretizou. Eis que a Covid-19 chegou e, entre dezembro/2019 a março/2020, se alastrou nos quatro cantos do mundo, diferentemente daquilo que aconteceu na África com o ebola e com a gripe suína, provocada por uma variação extremamente violenta do vírus H1N1, em 2009.

O enfrentamento da Covid-19 exige a difusão de práticas de higiene, já habituais, como lavar as mãos, cobrir a boca ou o nariz ao tossir ou espirrar. Novas medidas foram adotadas como o uso de máscaras e, principalmente, o distanciamento e isolamento social, popularmente difundidos com o slogan "fique em casa".

Essas medidas vêm sendo propagadas pela maioria dos governos estaduais e municipais. No caso do estado da Bahia, o Decreto Estadual n. 19.528 (2020) instituiu, no âmbito do Poder Executivo Estadual, o trabalho remoto como forma de promover o distanciamento social, alterando a rotina de trabalho.

O impacto imediato dessa medida afetou significativamente a área da educação em seus diversos níveis, considerando que o funcionamento dessa área vinha ocorrendo, predominantemente, com os atores interagindo em salas de aula. De outra parte, tanto a 
educação básica, quanto a educação superior possuem rotinas de gestão acadêmica e administrativa habitualmente conduzidas de maneira presencial.

Com efeito, a situação de pandemia e o mencionado Decreto, exigiram rápidas mudanças nos processos educacionais, especialmente, na gestão universitária. Por força da contingência, gestores, docentes e técnicos das Universidades Estaduais Baianas (Uebas), passaram a trabalhar remotamente em suas residências, empreendendo esforços para superarem dificuldades e manterem as rotinas por meio de mensagens via celular, e-mails, webconferências e lives, utilizando-se das plataformas disponibilizadas pelas instituições.

Os espaços físicos constituídos sob a clássica concepção administrativa para promover melhor funcionamento das estruturas organizacionais ou unidades de gestão universitária foram abruptamente subvertidos por espaços virtuais. Sobre essas estruturas, projetou-se a necessidade de nova conceituação de funcionamento e redefinição de estratégias na condução dos processos de gestão. O tempo e as condições apresentadas aos gestores diferem daqueles comumente adotados por meio das relações presenciais para a tomada de decisão. As expectativas, contudo, permanecem perenes.

Neste contexto, surge um novo paradigma para as Uebas no que concerne ao seu modelo de gestão administrativa e acadêmica. $O$ padrão de funcionamento, predominantemente presencial, até então adotado, foi redirecionado para a comunicação remota, utilizando-se das diversas mídias e plataformas disponíveis.

Ante esse novo paradigma, os fluxos e a dinâmica dos processos de gestão administrativa e acadêmica passaram a requerer dos gestores rápidas adaptações e respostas para situações que oscilam entre resultados precisos e imprecisos. De modo complementar, demanda ainda a tomada de decisão que oriente a Universidade Pública para o exercício de sua função social frente ao quadro de incertezas.

As demandas presentes nas rotineiras agendas estão circunstanciadas por um contexto pandêmico real e insofismável, sob o qual não se pode perder de vista que as decisões estão sendo tomadas em uma situação excepcional apoiadas, contudo, nas decisões dos Conselhos Superiores

Entre as demandas emergentes, estão aquelas associadas à necessidade de identificar 
alternativas à suspensão das atividades acadêmicas presenciais que compõem o semestre letivo e a permanente e intensa regularização dos processos acadêmicos. Incluem-se, ainda, a viabilização da pesquisa e da inovação, a realização de bancas de qualificação e defesa dos programas de pós-graduação, como também a manutenção da orientação aos mestrandos e doutorandos.

Importante salientar que a viabilidade desses processos é possível, considerando a utilização das diversas plataformas, disponibilizadas por meio do uso da Tecnologia Digital de Informação e Comunicação (TDIC), porém, restrita àqueles que possuem as competências digitais e acesso à internet e equipamentos adequados.

Face ao enfrentamento da pandemia e a necessidade de apresentar respostas às demandas sociais advindas desse contexto, as Uebas são demandadas, ainda, a contribuir para o provimento de profissionais da área da saúde, especialmente médicos, que venham a atuar em clínicas, postos de saúde, hospitais ou congêneres, a partir do instituto da revalidação de diplomas emitidos por instituições estrangeiras.

O processo de revalidação de diploma implica, para a instituição que revalida, assumir a responsabilidade de tornar o diplomado apto para o exercício da profissão no Brasil. Vale registrar que somente as universidades credenciadas ou recredenciadas, possuem a competência de registrar seus diplomas e, consequentemente, revalidar diplomas de graduação ou reconhecer diplomas de pós-graduação. Assim, estabeleceu-se um desafio entre os gestores das Uebas, qual seja: quais as bases institucionais adotadas pelas universidades estaduais baianas para promover a revalidação de diplomas emitidos por instituições estrangeiras?

Este artigo, portanto, objetiva apresentar a experiência da Universidade do Estado da Bahia (Uneb) com o processo de revalidação de diplomas de médicos emitidos por instituições estrangeiras. Experiência compartilhada com as demais Uebas, cuja iniciativa coaduna com a missão das instituições universitárias quanto à qualificação e capacitação permanentemente de pessoas, bem como a impulsão à pesquisa e o desenvolvimento científico.

Assim, o estudo ressalta a função social da universidade e, em decorrência desta, 
realiza a revisão da legislação sobre o assunto, adotando como referência a situação particular da Universidade do Estado da Bahia.

O cenário atual das universidades, expressa o entendimento de Kerr (1982), quanto à atuação dessas instituições em relação às transformações da sociedade, ou seja, passando de uma comunidade singular - uma comunidade de mestres e estudantes - para ser uma série de comunidades e de atividades interligadas sob um nome comum.

De outra parte, é importante situar os desafios da universidade no sentido de atenderem a multiplicidade de demandas sociais, políticas e do mundo do trabalho. De acordo com Santos (1997), os objetivos e finalidades da universidade se apresentam, por vezes, de forma dispersa, tal a sua característica de gestão multifacetada. Nesse contexto, a universidade procura ressignificar sua ação, buscando novas políticas de gestão que estabeleçam linhas de conexão entre sua ação institucional, as demandas do Estado e da sociedade.

Nesse cenário, a Uneb conjuntamente com as Uebas, tomou a iniciativa de propor um programa a ser implementado pelas quatro instituições estaduais de revalidação de diplomas suscitando, assim, esse estudo de natureza exploratória e descritiva. Inclui, também, uma pesquisa bibliográfica que aborda os tópicos "função social" e "autonomia universitária”, bem como da pesquisa documental, a exemplo da legislação que disciplina o processo de revalidação dos citados diplomas.

\section{Autonomia e Função Social da Instituição Universitária}

A Constituição Federal de 1988 (Art. 207), acompanhada pelas constituições estaduais, concede autonomia didático-científica, administrativa e de gestão financeira e patrimonial às universidades. Em um primeiro momento, entende-se por autonomia didáticocientífica a competência em estabelecer sua política de ensino, pesquisa e extensão, criar, modificar, fundir ou extinguir cursos, conferir graus, expedir diplomas e certificados, assim como outorgar bolsas, prêmios, títulos e outras dignidades universitárias (RANIERI, 2013).

No que concerne à autonomia administrativa, consiste na faculdade para elaborar e 
reformular o seu estatuto e normas complementares; regimentos geral e internos e manuais; dispor sobre o pessoal dos seus quadros docente, técnico-administrativo; prover os cargos de provimento temporário; contratar obras e serviços de que necessitar; apresentar ao chefe do Poder Executivo seus planos de cargos e salários, bem como os nomes para exercer os cargos de Reitor e Vice-Reitor escolhidos pela comunidade universitária.

Em seguida, a autonomia de gestão financeira e patrimonial retrata a competência da universidade para gerar e captar recursos, incorporar bens e recursos ao seu patrimônio, elaborar e administrar seu orçamento e plano de trabalho, manter em suas contas os saldos anuais dos respectivos recursos, contabilizando-os, como receita patrimonial por exercício civil.

Há que se registrar que a autonomia universitária não consegue se concretizar em sua plenitude nas universidades mantidas pelo poder público, por vezes, em consequência da tramitação e fluxo de processos no âmbito da administração pública, seja na esfera federal, estadual ou municipal, ou em virtude da dependência direta dos recursos repassados pelo Tesouro Federal, Estadual e Municipal. No entanto, para Ranieri (2013) a estrutura corporativa das universidades permitiu a preservação de alguma autonomia, em especial no que concerne à gestão acadêmica.

A mencionada autonomia, didática e científica (BRASIL, 1988) permite que as Uebas atinjam os objetivos estabelecidos no art. 262 da Constituição do Estado da Bahia de 1989, a saber:

I - produção e crítica do conhecimento científico, tecnológico e cultural, facilitando seu acesso e difusão;

II - participação na elaboração das políticas científica, tecnológica e de educação do Estado;

III - formação de profissionais;

IV - participação e contribuição para o crescimento da comunidade em que se insere e a resolução de seus problemas.

Compreende-se que a instituição universitária é uma unidade social criada com fim específico de desenvolver ensino, pesquisa e extensão. Possui divisão funcional exercida, em geral, por docentes e técnicos administrativos, portanto, com características de uma 
organização.

Acrescenta-se, contudo, que as universidades são organizações caracterizadas como complexas, resultado do papel social que desempenham na formação de profissionais e da cidadania, o conhecimento que socializam, a tecnologia que desenvolvem e utilizam, a convivência que possibilitam, o modelo de decisão colegiada que adotam e o quadro docente especializado por área de conhecimento (FINGER, 1988).

Para Pusser (2003), compreender o comportamento organizacional da universidade se constitui em um desafio, considerando que essa instituição pode ser vista como um sistema complexo, envolto em interesses difusos que não se dobram à lógica racional dos modelos organizacionais. A outra razão consiste na tradição colegiada que privilegia a gestão compartilhada e o consenso, o que torna difícil identificar preferências individuais, fundamentais para a aplicação de modelos da ciência política.

Salienta-se que o perfil de organização não exclui a condição de instituição social, conceituada como uma estrutura criada em decorrência de necessidades sociais básicas. Para Marilena Chauí (2003), a universidade é criada com reconhecimento público de sua legitimidade e de suas atribuições, é também estruturada por ordenamentos, regras, normas e valores que a definem como uma instituição social.

A autora enfatiza que a instituição universitária expressa a estrutura e o funcionamento da sociedade na qual atua. Assim, é possível observar na sua atividade, uma diversidade de opiniões, atitudes e projetos que ressaltam as divisões e contradições da sociedade.

Como instituição com função social, conforme explica Carlos Roberto dos Santos (2003), a universidade representa um segmento da sociedade, resultando, até certo ponto, quando da sua criação, em um modelo instituído pelo próprio contexto no qual está inserida nos seus aspectos social, político, econômico, religioso e ideológico, evidenciando-se uma estreita integração entre a criação da universidade e o lugar que esta ocupa na sociedade.

Dessa forma, em atenção ao estado de pandemia imposto pelo Covid-19, há evidente demanda de profissionais de saúde a fim de garantir o atendimento aos cidadãos baianos, no sentido de preservar as vidas. Portanto, a iniciativa das Uebas em constituir um programa de 
revalidação de diplomas emitidos por instituições estrangeiras, encontra respaldo na autonomia didática e científica, atinente à competência de emissão e registro de diplomas e, ao mesmo tempo, reforça a função social da instituição universitária. Enfatiza-se que este artigo versa sobre o citado processo de revalidação no âmbito da Universidade do Estado da Bahia, com base na legislação vigente.

\section{Bases gerais da legislação}

Apoiada no art. 207 da Constituição Federal do Brasil, bem como no § $1^{\circ}$, do art. 262 da Constituição do Estado da Bahia, a Uneb vem exercendo sua autonomia. Esta prerrogativa constitucional é direcionada ao exercício da autonomia didática e científica, administrativa e de gestão financeira e patrimonial.

No que tangem às especificidades dessa autonomia, há que se observar o art. $48 \mathrm{e}$ respectivos parágrafos, da Lei n. 9.394 (1996), Lei de Diretrizes e Bases da Educação Nacional (LDBN), conforme segue;

Art. 48. Os diplomas de cursos superiores reconhecidos, quando registrados, terão validade nacional como prova da formação recebida por seu titular.

$\S 1^{\circ}$ Os diplomas expedidos pelas universidades serão por elas próprias registrados, e aqueles conferidos por instituições nãouniversitárias serão registrados em universidades indicadas pelo Conselho Nacional de Educação.

$\S 2^{\circ}$ Os diplomas de graduação expedidos por universidades estrangeiras serão revalidados por universidades públicas que tenham curso do mesmo nível e área ou equivalente, respeitando-se os acordos internacionais de reciprocidade ou equiparação. (Brasil, 1996).

De modo a regulamentar os dispositivos da LDBN aqui mencionados, o Conselho Nacional de Educação (CNE) e a Câmara de Educação Superior (CES) emitiram a Resolução n. 12 (2007), que disciplina que o registro dos diplomas expedidos por instituições nãouniversitárias está a cargo das universidades credenciadas. Posteriormente, o CNE expediu a Resolução n. 3 (2016), a qual “dispõe sobre normas referentes à revalidação de diplomas de cursos de graduação e ao reconhecimento de diplomas de pós-graduação stricto sensu, 
expedidos por estabelecimentos estrangeiros de ensino superior " e prevê:

Art. $1^{\circ}$ Os diplomas de cursos de graduação e de pós-graduação stricto sensu (mestrado e doutorado), expedidos por instituições estrangeiras de educação superior e pesquisa, legalmente constituídas para esse fim em seus países de origem, poderão ser declarados equivalentes aos concedidos no Brasil e hábeis para os fins previstos em lei, mediante processo de revalidação ou reconhecimento, respectivamente, por instituição de educação superior brasileira, nos termos da presente Resolução.

Parágrafo único. Os processos de revalidação e de reconhecimento devem ser fundamentados em análise relativa ao mérito e às condições acadêmicas do programa efetivamente cursado pelo(a) interessado(a), levando em consideração diferenças existentes entre as formas de funcionamento dos sistemas educacionais, das instituições e dos cursos em países distintos.(CNE, Resolução n ${ }^{\circ} 3$ )

No que concerne a revalidação de diplomas de cursos de graduação obtidos no exterior, o art. $3^{\circ}$ da referida Resolução define que poderão ser revalidados por universidades brasileiras, regularmente credenciadas, criadas e mantidas pelo poder público, que tenham curso reconhecido do mesmo nível e área ou equivalente. $\mathrm{O}$ art. $6^{\circ}$, da mesma Resolução, enfatiza que o processo de revalidação prevê a avaliação global das condições acadêmicas de funcionamento do curso de origem, a saber:

- as informações apresentadas pelo(a) requerente no processo, especialmente quanto à estrutura do currículo, perfil do corpo docente, ao processo de integralização do curso e avaliação de desempenho do estudante;

- cursos estrangeiros com estrutura curricular ou de organização acadêmica diferentes dos cursos da mesma área existente na universidade brasileira que procederá a revalidação do diploma;

- a instituição universitária brasileira que procederá revalidação do diploma poderá organizar comitês de avaliação com professores externos ao seu corpo docente, que possuam perfil acadêmico adequado à avaliação do processo específico.

Para efeito de orientação geral, de acordo com o disposto nos artigos 16 e 17, a análise dos pedidos de revalidação de diplomas pelas universidades será realizada por universidade pública que tenha curso do mesmo nível e área ou equivalente, respeitando-se os acordos internacionais de reciprocidade ou equiparação, conforme orientação contida na Resolução 
CNE/CES no 3, de 2016, através da avaliação global das condições acadêmicas de funcionamento do curso de origem, a exemplo de competências e habilidades e o processo de oferta na instituição de origem.

No que tange particularmente a revalidação de diplomas de médicos expedidos por universidades estrangeiras, o MEC e o Ministério da Saúde (MS) editaram a Portaria Interministerial n. 278 (2011), instituindo o Exame Nacional de Revalidação de Diplomas Médicos (Revalida), o qual subsidia os procedimentos de revalidação conduzidos por universidades públicas.

Em 2019, a Secretaria de Educação Superior, através da Portaria n. 17, constituiu Grupo de Trabalho para promover estudos e aperfeiçoar os procedimentos de revalidação dos diplomas de medicina. Posteriormente, foi promulgada a Lei n. 13.959 (2019), que instituiu uma nova versão para o Revalida, com caraterística normativa mais forte.

Ainda no contexto das iniciativas do MEC, se apresenta a Plataforma Carolina Bori, criada a partir da Portaria Normativa n. 22 (2016), com o "objetivo de subsidiar a execução e a gestão dos processos de revalidação e reconhecimento de diplomas". Este ambiente informatizado destina-se, ainda, a facilitar o controle e o fluxo dos processos de revalidação/reconhecimento e gerar maior grau de interatividade entre as partes interessadas. Ressalta-se que a Uneb está cadastrada nesta Plataforma, à qual vem sendo utilizada para o reconhecimento de diplomas de pós-graduação stricto sensu emitidos por instituições estrangeiras.

\section{A experiência da Uneb}

Consubstanciada, portanto, nas Constituições Federal e Estadual da Bahia, na LDBN, nos seus Estatuto e Regimento Geral (2011), a Uneb vem constituindo normas complementares para orientar que os Órgãos integrantes da Administração Superior, da Administração Setorial, Suplementares e os de Apoio Acadêmico-Administrativo, exerçam suas atribuições.

Entre as atribuições institucionais, estão aquelas relativas aos processos acadêmicos 
decorrentes de instituições estrangeiras. Nesse caso, o Regimento Geral orienta esses processos sob duas perspectivas: (i) aquela que atribui ao Conselho Superior de Ensino e Pesquisa (Consepe), conforme o inciso XIII, do artigo 14, a competência para "convalidar ou revalidar estudos de nível superior realizados no âmbito nacional ou em outros países, observada a legislação aplicável"; e (ii) aquela que atribui a esse mesmo Órgão a competência para definir normas relativas à revalidação de diplomas dos cursos de mestrado e doutorado, conforme o parágrafo único do artigo 281:

Os diplomas e certificados quando emitidos por Instituições estrangeiras poderão ser revalidados mediante processo que obedecerá às normas definidas pelo CONSEPE e este em observância às determinações legais na espécie (UNEB, 2012).

E, de modo particular, este Regimento, no parágrafo $2^{\circ}$, do artigo 283, orienta sobre o registro dos diplomas dos cursos superiores da Universidade:

Art. 283. Os diplomas dos cursos de graduação, pós-graduação stricto sensu e os certificados de cursos seqüenciais, extensão e pósgraduação lato sensu serão expedidos pela Secretaria Especial de Registros de Diplomas e Certificados (SERDIC), bem como registrados em livros próprios.

[...]

$\S 2^{\circ}$ A Universidade procederá ao registro dos diplomas de seus próprios cursos superiores, de graduação e pós-graduação, desde que reconhecidos, bem como dos diplomas de graduação e pósgraduação, emitidos por Instituições ou Universidades estrangeiras, para que possuam validade nacional como prova da formação recebida pelo titular e como requisito para o exercício profissional (UNEB, 2013).

$\mathrm{Na}$ esteira desse assunto, o Conselho Universitário da Uneb (Consu) emitiu a Resolução n. 840 (2011), a qual no artigo $1^{\circ}$, regulamenta o "procedimento para o registro de diplomas de cursos de graduação (licenciaturas, bacharelados e tecnológicos) e sequenciais de formação específica expedidos por instituições não-universitárias".

Registre-se que, para o efetivo encaminhamento do processo de registro de diplomas, a Resolução apresenta em seu artigo $3^{\circ}$ e seguintes, os critérios e procedimentos para obtenção do registro de diplomas. Por fim, o artigo $4^{\circ}$ atribui à Serdic, a conferência da 
documentação requerida no artigo. $3^{\circ}$, a fim de emitir parecer conclusivo concernente ao registro dos diplomas.

O Conselho Universitário emitiu, ainda, a Resolução n. 1.240 (2016), que estabelece critérios e procedimentos referentes ao reconhecimento de diplomas de mestre e doutor expedidos por instituições estrangeiras de ensino superior, no âmbito da Uneb, conforme definidos no anexo da mesma.

Do mesmo modo, observa-se que a mencionada Resolução definiu, em seu art. $3^{\circ} \mathrm{e}$ respectivos parágrafos, incisos e alíneas, critérios e orientações concernentes à efetivação reconhecimento de diplomas de mestre e doutor expedidos por instituições estrangeiras de ensino superior.

Nota-se, no art. $5^{\circ}$ desta Resolução, que o processo de reconhecimento requer a constituição de um comitê de avaliação, composto por um máximo de 03 (três) professores vinculados ou designados pelo Programa competente, com qualificação compatível à área de conhecimento e nível do título a ser reconhecido.

De acordo com o art. $7^{\circ}$ da mesma Resolução, o referido comitê tem a atribuição de emitir parecer conclusivo, de modo a encaminhar à Coordenação do Programa que remeterá ao Consepe para, por fim, encaminhar à Serdic, que emitirá o documento competente.

Ante ao exposto, observa-se que, no exercício de sua autonomia, a Uneb vem normatizando seus processos acadêmicos. Portanto, encontra-se em condição institucional de responder às demandas sociais emergentes, no caso particular, para a regulamentação de revalidação de diplomas de médicos emitidos por instituições estrangeiras.

Em específico à composição do processo de revalidação do diploma aqui em discussão, há que se observar o que prevê a Resolução do CNE/CES n. 3 (2014), a qual institui as Diretrizes Curriculares Nacionais do Curso de Graduação em Medicina, conforme orienta a já mencionada Portaria Normativa n. 22 (2016). Neste contexto, no Brasil,

Art. $3^{\circ} \mathrm{O}$ graduado em Medicina terá formação geral, humanista, crítica, reflexiva e ética, com capacidade para atuar nos diferentes níveis de atenção à saúde, com ações de promoção, prevenção, recuperação e reabilitação da saúde, nos âmbitos individual e coletivo, com responsabilidade social e compromisso com a defesa 
da cidadania, da dignidade humana, da saúde integral do ser humano e tendo como transversalidade em sua prática, sempre, a determinação social do processo de saúde e doença.

Em complementação, os artigos $4^{\circ}, 5^{\circ}, 6^{\circ}$ e $7^{\circ}$ da mesma Resolução, definem que a formação do graduado em medicina compreende as seguintes áreas:

- Atenção à saúde, com ênfase nas dimensões da diversidade biológica, subjetiva, étnico-racial, de gênero, orientação sexual, socioeconômica, política, ambiental, cultural, ética e demais aspectos que compõem o espectro da diversidade humana e particularizam cada pessoa ou cada grupo social;

- Gestão em saúde, que diz respeito à capacidade de compreender os princípios, diretrizes e políticas do sistema de saúde, e participar de ações de gerenciamento e administração para promover o bem-estar da comunidade;

- Educação em saúde, a qual aborda a corresponsabilização do profissional médico pela própria formação inicial, continuada e em serviço, autonomia intelectual, responsabilidade social, bem como o compromisso com a formação das futuras gerações de profissionais de saúde, e o estímulo à mobilidade acadêmica e profissional.

Registra-se que o diploma revalidado tem impacto direto para e na sociedade brasileira, considerando que o profissional, ao receber o novo documento, estará apto para exercer sua função em igual condição àquele profissional que tenha cursado a graduação no Brasil.

Complementando as informações concernentes ao exercício da medicina em nosso país, verifica-se também o expresso no art. $8^{\circ}$ da mencionada Resolução n. 3, do CNE/CES, quando aborda de maneira direta a conversão do conteúdo das Diretrizes e componentes curriculares, "em efetivas práticas competentes, adequadas e oportunas, as iniciativas e ações esperadas do egresso, agrupar-se-ão nas respectivas Áreas de Competência”. Acrescenta o parágrafo único que 
com utilização dos recursos disponíveis, e exprimindo-se em iniciativas e ações que traduzem desempenhos capazes de solucionar, com pertinência, oportunidade e sucesso, os desafios que se apresentam à prática profissional, em diferentes contextos do trabalho em saúde, traduzindo a excelência da prática médica, prioritariamente nos cenários do Sistema Único de Saúde (SUS). (CNE, Resolução n³, 2014)

Entendemos, portanto, que o processo de revalidação deve contemplar as especificidades pontuadas nas Diretrizes Curriculares de forma a garantir experiência e vivência no Sistema Único de Saúde (SUS). Situação reforçada no art. 24, quando é discutido o estágio curricular obrigatório de formação em serviço, em regime de internato, sob supervisão, em serviços próprios da instituição responsável pela oferta do curso, convênio ou em regime de parcerias estabelecidas por meio de Contrato Organizativo da Ação Pública Ensino-Saúde com as Secretarias Municipais e Estaduais de Saúde, conforme previsto no art. 12 da Lei $\mathrm{n}^{\circ}$ 12.871, de 22 de outubro de 2013.

\section{Considerações Finais}

Pode-se observar que as Uebas e, em particular, a Universidade do Estado da Bahia, dispõem de um aparato legal e normativo capaz de orientar suas iniciativas de revalidação de diplomas emitidos por instituições de ensino superior estrangeiras.

Este estudo procurou demonstrar os principais elementos constitutivos da legislação específica ao assunto, apontando caminhos que podem ser adotados para balizar os órgãos competentes das universidades e seus gestores na discussão e tomada de decisão sobre a revalidação de diplomas.

É importante destacar que o arcabouço normativo que apoia e orienta a autonomia de gestão financeira e patrimonial, concede-lhe também a competência para gerar e captar recursos, incorporar bens e recursos ao seu patrimônio, elaborar e administrar seu orçamento, entre outros. Apoiada, portanto, no arcabouço normativo, descrito nesse artigo e, sobretudo, nas instâncias deliberativas que integram a estrutura organizacional da Universidade, foram geradas as normas que orientam revalidação de diplomas emitidos por instituições de ensino superior estrangeiras, no âmbito da Uneb. 
A despeito das polêmicas em torno da matéria, especialmente, manifestadas por aqueles que consideram que o processo federal de revalidação de diplomas, a partir do Exame Nacional de Revalidação de Diplomas Médicos (Revalida), do Ministério da Educação, atende as demandas atuais, as discussões no âmbito da Uneb evoluíram no sentido de manter um alinhamento com as universidades estaduais e criando processo próprio de revalidação de diplomas.

A decisão das universidades estaduais baianas em constituir um programa próprio de revalidação de diplomas emitidos por instituições estrangeiras, se apresentou como uma estratégia singular, na medida em que convergiu para o consenso em um cenário plural e divergente.

Essas universidades se respaldaram na autonomia didática e científica, previstas nas normas que conferem a competência para emitir e registrar diplomas. De outra parte, essas instituições cumpriram sua função política e social de engajamento com os macroproblemas que afetam a sociedade.

Cabe salientar que o atual contexto de pandemia, aqui descrito, torna esse assunto altamente relevante. Os subsídios aqui apresentados foram constituídos com o propósito de clarear as dúvidas em torno do assunto e contribuir para minimizar a carência de profissionais de saúde, especialmente médicos. A experiência vivenciada pelas universidades estaduais baianas, em particular, pela Uneb, representa um sinal de unidade, na diversidade. E, ressalta, o importante enfrentamento dos dilemas contemporâneos vivenciados pelas instituições de ensino superior, no que concerne ao exercício da autonomia universitária.

Por fim, ressalta-se que a revalidação de diplomas se tornou um processo acadêmico permanente, com o qual as universidades devem se preparar para conviver e fornecer respostas para essa importante demanda contemporânea.

\section{Referências}


BAHIA. Constituição do Estado da Bahia, de 05 de outubro de 1989. Salvador, BA. Disponível em: < http://www.legislabahia.ba.gov.br/documentos/constituicao-do-estadoda-bahia-de-05-de-outubro-de-1989> Acesso em: 05 Jul 2020.

Decreto n. 19.528, de 16 de março de 2020. (2020). Institui, no âmbito do Poder Executivo Estadual, o trabalho remoto, na forma que indica, e dá outras providências. Salvador, BA. Recuperado de http://www.legislabahia.ba.gov.br/documentos/decreto-no19528-de-16-de-marco-de-2020

BRASIL. Constituição da República Federativa do Brasil, de 5 de outubro de 1988. Disponível em: $<$ http://www.planalto.gov.br/ccivil_03/constituicao/constituicao.htm> Acesso em: 05 Jul 2020.

. Lei Federal no 9.394, de 20 de dezembro de 1996. (1996). Estabelece as diretrizes e bases da educação nacional. Disponível em: < http://www.planalto.gov.br/ccivil_03/leis/19394.htm> Acesso em 20 Ago 2020.

Resolução n. 12, de 13 de dezembro de 2007. (2007). Dispõe sobre o registro de diplomas expedidos por instituições não-universitárias. Brasília, DF. Recuperado de http://portal.mec.gov.br/cne/arquivos/pdf/2007/rces012_07.pdf

Portaria Interministerial n. 278, de 17 de março de 2011. (2011). Institui o Exame Nacional de Revalidação de Diplomas Médicos expedidos por universidades estrangeiras. Brasília, DF. Recuperado de http://download.inep.gov.br/educacao_superior/revalida/portaria/2011/portaria_n278 1703 2011 revalida.pdf

Lei n. 12.871, de 22 de outubro de 2013. Institui o Programa Mais Médicos, altera as Leis $\mathrm{n}^{\mathrm{o}}$ 8.745, de 9 de dezembro de 1993, e $\mathrm{n}^{\mathrm{o}}$ 6.932, de 7 de julho de 1981, e dá outras providências. Brasília, DF. Recuperado de http://www.planalto.gov.br/ccivil 03/_Ato2011$\underline{\text { 2014/2013/Lei/L12871.htm }}$

Resolução do n. 3, de 20 de junho de 2014. (2014). Institui Diretrizes Curriculares Nacionais do Curso de Graduação em Medicina e dá outras providências. Brasília, DF. Recuperado de https://abmes.org.br/arquivos/legislacoes/Res-CES-CNE-003-2014-06$\underline{20 . p d f}$

Resolução n. 3, de 22 de Junho de 2016. (2016). Dispõe sobre normas referentes à revalidação de diplomas de cursos de graduação e ao reconhecimento de diplomas de pósgraduação stricto sensu (mestrado e doutorado), expedidos por estabelecimentos estrangeiros de ensino superior. Recuperado de http://www.in.gov.br/materia//asset publisher/Kujrw0TZC2Mb/content/id/21652040/do1-2016-06-23-resolucao-n-3-de22-de-junho-de-2016-21651958 
Portaria Normativa n. 22, de 13 de dezembro de 2016. (2016). Dispõe sobre normas e procedimentos gerais de tramitação de processos de solicitação de revalidação de diplomas de graduação estrangeiros e ao reconhecimento de diplomas de pós-graduação stricto sensu (mestrado e doutorado), expedidos por estabelecimentos estrangeiros de ensino superior. Brasília, DF. Recuperado de http://www.in.gov.br/materia//asset_publisher/Kujrw0TZC2Mb/content/id/22190733/do1-2016-12-14-portarianormativa-n-22-de-13-de-dezembro-de-2016-22190702

Portaria n. 17, de 15 de maio de 2019. (2019). Institui Grupo de Trabalho com a finalidade de promover estudos e propor medidas visando ao aperfeiçoamento do processo de revalidação dos diplomas de graduação em Medicina. Brasília, DF. Recuperado de http://www.in.gov.br/web/dou/-/portaria-n\%C2\%BA-17-de-15-de-maio-de-2019101781115

Lei n. 13.959, de 18 de dezembro de 2019. (2019). Institui o Exame Nacional de Revalidação de Diplomas Médicos Expedidos por Instituição de Educação Superior Estrangeira (Revalida). Brasília, DF. Recuperado de http://www.planalto.gov.br/ccivil_03/ ato2019-2022/2019/lei/L13959.htm

CHAUÍ, Marilena. A universidade pública sob nova perspectiva. Revista Brasileira de Educação. São Paulo: n 24, set/out/nov, 2003, p. 5-15.

FINGER, Almeri Paulo, Gestão Acadêmica In: FINGER, Almeri P. (Org.). Universidade: Organização e Planejamento. Florianópolis: UFSC/CPGA/NUPEAU, 1988, p. 71-88.

KERR, Clark. Os usos da Universidade. Fortaleza: CE: UFC, 1982. p. 19-36. PUSSER, Brian, Beyond Ballridge: extending the political model of higher education organization and governance. Educational Policy, vol 17, nº 1, p. 121-140: 2003.

RANIERI, N. Autonomia Universitária: as universidades públicas e a Constituição Federal de 1988. 2. ed. São Paulo: Imprensa Oficial do Estado de São Paulo, 2013.

SANTOS, Boaventura de Souza. Pela mão de Alice: o social e o político na transição pósmoderna. São Paulo: Cortez, 1997.

SANTOS, Carlos Roberto A. dos. A Nova Missão da Universidade: a inclusão social. In: Revista de Educação CEAP. Salvador: a. 11, n. 42, set-nov/2003, p. 21-28.

UNIVERSIDADE DO ESTADO DA BAHIA. Resolução CONSU n. 840, de 27 de julho de 2011. (2011). Dispõe sobre os procedimentos para registro, pela UNEB, de diplomas expedidos por instituições não-universitárias. Salvador, BA. Recuperado de https://portal.uneb.br/conselhos/wp-

content/uploads/sites/103/2020/03/RESOLU $\% \mathrm{C} 3 \% 87 \% \mathrm{C} 3 \% 83 \mathrm{O}-\mathrm{N} \% \mathrm{C} 2 \% \mathrm{BA}-$ $\underline{840 \text { 2011.pdf }}$ 


\section{REVISTA DE ADMINISTRAÇÃO EDUCACIONAL}

\section{ISSN -2359-1382}

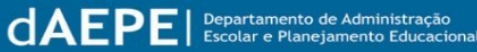

Resolução CONSU n. 864, de 19 de novembro de 2011. (2011). Aprova o Regimento Geral da Universidade do Estado da Bahia. Salvador, BA. Recuperado de https://portal.uneb.br/wp-content/uploads/2018/09/REGIMENTO-GERAL-DA-UNEB2012.pdf

Resolução CONSEPE n. 1.240, de 17 de outubro de 2016. (2016). Estabelece critérios e procedimentos referentes ao reconhecimento de diplomas de Mestre e Doutor expedidos por Instituições Estrangeiras de Ensino Superior, no âmbito da UNEB e dá outras providências. Salvador, BA. Recuperado de https://portal.uneb.br/ppg/wpcontent/uploads/sites/58/2018/05/1240-consu-Res.-Reconhecimento-Diploma-Mestre-eDoutor-COM-MARCA $\% \mathrm{C} 3 \% 87 \% \mathrm{C} 3 \% 95 \mathrm{ES}-\mathrm{CONSEPE.pdf}$

Enviado em: 20/09/2020

Revisado em: 13/06/2021

Aceito em:16/08/2021 